\title{
PDE -5 inhibitors' implications in women: Are they of help?
}

\author{
Review \\ Article
}

\author{
Taymour Mostafa
}

Department of Andrology and Sexology, Faculty of Medicine, Cairo University, Cairo, Egypt

\begin{abstract}
Introduction: Introduction of the oral phosphodiesterase isoenzyme-5 inhibitors (PDE5-Is) has revolutionized sexual medicine by affording effective treatment for erectile dysfunction. PDE5 hydrolyses cyclic GMP specifically to 5'-GMP. Since its launching, PDE5-Is have stimulated scientific interest for their impending benefits in various implications for the welfare of the human beings.

Aim: To highlight the possible potential implications of PDE5-Is in women.

Participants and methods: A systematic review was carried out till June 2017 based on a search of concerned articles in Medline, medical subject heading databases, Scopus, The Cochrane Library, Embase, and CINAHL databases without language restriction. Keywords used to assess that outcome and concerned associations were PDE5 inhibitors, sildenafil, tadalafil, vardenafil, avanafil, women, and females.

Main outcome measures: Different implications for PDE5-Is in women.

Results: Oral PDE5-Is have beneficial medical implications in women. Sexual implications include female sexual dysfunction, female sexual arousal disorder, antidepressant-associated sexual dysfunction, and affected relationship. Gynecological implications include endometrial thickness, abortion, preeclampsia, fetal growth restriction, clitoral engorgement, primary dysmenorrhea, uterine blood flow, oligohydramnios, poor ovarian response, ovarian ischemia/reperfusion, and uterine contractility. Urological implications include overactive bladder and interstitial cystitis, whereas dermatological implications include systemic sclerosis and cellulite. In addition, PDE5-Is proved to be beneficial in pulmonary arterial hypertension, coronary dysfunction, esophageal motility, and some metabolic effects.

Conclusion: Oral PDE5-Is are an eye-catching therapeutic class of agents with beneficial effects for women, which could be potentially applied after well-designed clinical trials.
\end{abstract}

Key Words: Females, female sexual dysfunction, phosphodiesterase isoenzyme-5 inhibitors, sildenafil, tadalafil, vardenafil, women

Received: 31 March 2019, Accepted: 1 April 2019

Corresponding Author: Taymour Mostafa, MD, Department of Andrology and Sexology, Faculty of Medicine, Cairo University, Cairo, Egypt, Tel.: +2 01005150297, E-mail: taymour1155@link.net

ISSN: 2090-6048, December 2018 Vol.8, No.4

\section{INTRODUCTION}

Nowadays, oral phosphodiesterase isoenzyme-5 inhibitors (PDE5-Is) are considered the first-line therapy for erectile dysfunction $(E D)^{[1]}$. Specifically, PDE5 hydrolyses cyclic cGMP to 5'-GMP by blocking cGMP hydrolysis, and potentiates the effects of cGMP resulting in decreased intracellular calcium leading to penile smooth muscle relaxation and vasodilatation with increased penile blood flow ${ }^{[2-5]}$. As well, this family demonstrated significant antiapoptotic and antioxidant properties ${ }^{[6-8]}$. Four orally PDE5-Is were approved by the Food and Drug Administration (FDA), namely, sildenafil, vardenafil, tadalafil, and avanafil. Sildenafil citrate was the first to be released at 1998 with maximal plasma concentration (Tmax) at 60 min on empty stomach and acts for 4-6 $\mathrm{h}^{[9]}$. Vardenafil hydrochloride was approved at 2003 with Tmax of 60 min on empty stomach and acts for up to 7 $\mathrm{h}^{[10]}$. Tadalafil was approved at 2003 of Tmax of $120 \mathrm{~min}$ with duration of action up to $36 \mathrm{~h}$ and is not affected by food $^{[11,12]}$. Avanafil was approved in 2012 with Tmax 30 45 min on empty stomach establishing coitus as early as 10 $\min ^{[13]}$. PDE5-Is' high tolerability made them an attractive tool to investigate further physiological functions beyond ED with collateral benefits for multitude of nonsexual implications $^{[14-18]}$.

This review aimed to highlight the potential nonsexual implications of PDE5-Is in women.

\section{Sexual implications}

\section{Female sexual dysfunction}

Female sexual dysfunction (FSD) is defined as a disorder of sexual desire, arousal, or orgasm, and/or sexual pain, which results in personal distress and affects quality of life and interpersonal relationships ${ }^{[19]}$. The pathophysiology, diagnosis, and treatment of female sexual interest in preand post-menopausal women present a complex arena. Lately, flibanserin was approved by the US FDA in August 2015 as the first pharmacologic treatment for hypoactive 
sexual desire disorder (HSDD) in premenopausal women $^{[20,21]}$. Testosterone, buspirone, sildenafil, bupropion, bremelanotide, and herbal medications have verified some clinical benefits in women with FSD but with significant design, dosing, or generalizability limitations. Discordance between genital and subjective measures of sexual response in women may be augmented by PDE5 effects on genital vasocongestion rendering successful treatment unlikely via pharmacological treatment alone ${ }^{[22]}$.

In their study, Caruso et al. ${ }^{[23]}$ suggested that sildenafil may improve sexual performance of women affected by sexual difficulties such as arousal disorder and may indirectly improve other aspects of sexual life. Caruso et al. ${ }^{[24]}$ showed that sildenafil improved arousal, orgasm, and enjoyment with respect to placebo. Significant differences were noted during sildenafil use with respect to the baseline for arousal, orgasm, and sexual enjoyment. It is suggested that sildenafil acts on the different sexual pathways in healthy women, improving their sexual experience.

Dasgupta et al. ${ }^{[25]}$ assessed the effects of sildenafil in women with multiple sclerosis and sexual dysfunction. Significant improvement following sildenafil was reported in the lubrication domain of sexual function during the double-blind phase with a significant correlation between the latency of tibial and pudendal evoked potentials. Ferrara et al. ${ }^{[26]}$ presented a case report of neurogenic FSD owing to ruptured L5-S1 intervertebral disk treated with 50-mg sildenafil, and her symptoms were recorded using a FSFI score. The patient reported a good response with subjective increase in vaginal blood flow, achieved better vaginal lubrication, and noted more clitoral engorgement.

Snoeren et al. ${ }^{[27]}$ supported the finding that combination treatment of testosterone and vardenafil could be used as a treatment for women with HSDD. van der Made et al. ${ }^{[28]}$ demonstrated that the combination of testosterone and vardenafil could increase the sensitivity for sexual stimuli and improve the desire and arousal components of the sexual response. In an initially low-attention for sexual cues group, preconscious attentional bias for sexual cues increased under the testosterone condition. In these women, the combination of testosterone and vardenafil caused an improvement in genital response and subjective indices of sexual function. In the group that had initially a high attention for sexual cues, preconscious attentional bias for sexual cues decreased under the condition of testosterone. van der Made et al. ${ }^{[29]}$ assessed if the combination of testosterone and vardenafil causes an increase in sensitivity for sexual cues and an increase in the physiological sexual responding in women with HSDD. In women without childhood sexual abuse, testosterone appears to activate central sexual mechanisms resulting in higher vaginal pulse amplitude under the combination of testosterone and vardenafil.

Zeinalzadeh et al. ${ }^{[30]}$ assessed women with HSDD using the FSFI and Spielberger's questionnaire. They were divided into Elaeagnus angustifolia flower ( $4.5 \mathrm{~g} /$ day for 35 days), sildenafil tablet (50 $\mathrm{mg}$ for 4 weeks), and controls. In the sildenafil group, the mean score of state anxiety decreased from 22.15 to 20.1 and that of trait anxiety decreased from 23.07 to 21.55 after the intervention.

Poels et al. ${ }^{[31]}$ showed that on-demand T+PDE5i is a potentially promising treatment for women with HSDD, particularly in women with low sensitivity for sexual cues. Poels et al. ${ }^{[32]}$ suggested two new on-demand drug treatments for women with HSDD/Female Sexual Interest/ Arousal Disorder (FSIAD) based on different causal mechanisms. Testosterone combined with a PDE5 inhibitor has been developed for women with HSDD/FSIAD owing to a relatively insensitive system for sexual cues, whereas testosterone combined with a serotonin $1 \mathrm{~A}$ receptor agonist has been used for women with HSDD/FSIAD owing to dysfunctional activation of sexual inhibitory mechanisms.

Akbarzadeh et al. ${ }^{[33]}$ compared the effect of Elaeagnus angustifolia flower extract and sildenafil on female orgasmic disorder. The first group had to consume $4.5 \mathrm{gr}$ of E. angustifolia extract in two divided doses for 35 days and the second used 50-mg sildenafil tablets for 4 weeks 1 $\mathrm{h}$ before coitus. The frequency of orgasmic disorder before the intervention was $41.5,40.5$, and $57.1 \%$ compared with $29.3,16.7$, and $50 \%$ after the intervention in the Elaeagnus angustifolia, sildenafil, and control groups, respectively. The highest reduction of changes after the intervention $(58.8 \%)$ was observed in the sildenafil group. Borghi et al. ${ }^{[34]}$ showed that PDE5 inhibitors could be an effective option for many subtypes of FSD, with improvement in many aspects of sexual function, such as desire, arousal, orgasm, and sexual satisfaction.

Alp et al.${ }^{[35]}$ investigated the effects of PDE-5 inhibitors on osteoporosis by the $\mathrm{NO} / 3^{\prime}, 5^{\prime}$-cGMP/protein kinase $\mathrm{G}$ signalling pathway on female rats. The first group was healthy controls with no ovariectomy, whereas other groups underwent a bilateral ovariectomy. Six months after ovariectomy, vardenafil, udenafil, and tadalafil were given to the third, fourth, and fifth groups but not to the positive control $(10 \mathrm{mg} / \mathrm{kg} /$ day for 2 months). These inhibitors may have caused a positive effect on the increased bone mass density and reduction of bone resorption markers. There were positive effects of PDE5 inhibitors on oxidative stress, increased angiogenesis in bone tissue, and improved reformation rate of bone in rats with osteoporosis.

\section{Female sexual arousal disorder}

FSAD is a common disorder encountered in clinical practice, with self-reported arousal difficulties ${ }^{[36]}$. FSAD is a heterogeneous condition whose underlying causes are difficult to diagnose, and its appropriate treatment requires a thorough sexual, psychological, and medical history ${ }^{[37]}$. Several agents have been studied as possible treatments for FSAD, though none have received regulatory approval from the US FDA. These drugs include topical alprostadil, $\alpha$-adrenergic receptor antagonists, melatonin receptor agonists, and PDE inhibitors. PDE5 has been found to be 
expressed in vaginal, clitoral, and labial smooth muscle, indicating its involvement in female sexual functions, particularly genital arousa ${ }^{[38]} \mathrm{PDE} 5$, however, is expressed in smaller quantities in the female clitoris than in the male corpus cavernosum ${ }^{[39,40]}$.

Berman et al. ${ }^{[41]}$ determined the efficacy of sildenafil use in women with FSAD. Genital blood flow, vaginal lubrication, intravaginal pressure-volume changes, and genital sensation were recorded presexual and postsexual stimulation at baseline and following 100-mg sildenafil using a validated sexual function inventory at baseline and the following 6 weeks. Following sildenafil, poststimulation physiologic measurements improved significantly compared with baseline. Baseline subjective sexual function complaints such as low arousal, low desire, low sexual satisfaction, difficulty achieving orgasm, decreased vaginal lubrication, and dyspareunia also were improved significantly following 6-week home use of sildenafil.

Nevertheless, the presence of PDE5 in female genital tissue has supported the hypothesis that sildenafil may be useful in treating some forms of FSD, such as FSAD. In addition, the mechanism of action that sildenafil has on cellular tissue indicates that greater success would be achieved in the treatment of genital rather than subjective arousal disorder ${ }^{[42-44]}$. In their study, Claret et al. ${ }^{[45]}$ developed a model to explore the dose response of sildenafil in patients with FSAD based on telephone sexual activity daily diary data. Sildenafil showed a dose-dependent effect in patients with FSAD. Alexander et al. ${ }^{[46]}$ evaluated oral sildenafil in women with FSAD as a result of paraplegia/ tetraplegia in a 4-week baseline period followed by 12 weeks of treatment (50-100 mg or decreased to $25 \mathrm{mg}$ once during the treatment period). Sildenafil Sildenafiltreated women and placebo-treated women had an increase in their sexual activities. Omidi et al. ${ }^{[47]}$ compared the effects of 50-mg oral sildenafil $1 \mathrm{~h}$ before intercourse and weekly sessions cognitive-behavioral therapy for 8 weeks on women with arousal and orgasm dysfunction. The mean scores for the FSFI, sexual satisfaction, and the Enrich marital satisfaction scale were increased in both groups during treatment.

Caruso et al. ${ }^{[48]}$ determined whether daily tadalafil 5 $\mathrm{mg}$ is effective in type 1 premenopausal women affected by FSAD. Women reported quality-of-life improvement at the $12^{\text {th }}$ week follow-up with improved experience of sexual genital arousal/orgasm, sexual enjoyment, satisfaction by frequency of sexual activity, and frequency of sexual thoughts or fantasies. Moreover, dyspareunia was decreased with respect to baseline. After tadalafil administration, the mean peak systolic velocity increased, and the mean diastolic velocity was decreased, whereas the mean resistance index and the mean pulsatility index (PI) were significantly higher compared with the baseline values.

\section{Antidepressant-associated sexual dysfunction}

Administration of selective serotonin reuptake inhibitors (SSRIs) or serotonin and norepinephrine reuptake inhibitors relieves depressive symptoms but may cause sexual dysfunction in women that frequently results in premature treatment discontinuation. Many strategies have been reported to assist the patients in minimizing such impairment, with variable degrees of success, one of them is PDE5-Is. Fava et al. ${ }^{[49]}$ observed significant improvement in all domains of sexual functioning such as libido, arousal, orgasm, and sexual satisfaction, with $69 \%$ of patients reporting themselves as much/very much improved. In an open study ${ }^{[50]}$, sildenafil $50 \mathrm{mg}$ was prescribed for women reporting FSD induced by antidepressant medication, primarily SSRIs, $1 \mathrm{~h}$ before sexual activity. They were told to increase the dose to $100 \mathrm{mg}$ on the next occasion if experienced either partial or a lack of response. These patients, all of whom had experienced either anorgasmia or delayed orgasm with/without associated disturbances, reported significant reversal of sexual dysfunction, usually with the first dose of $50 \mathrm{mg}$ of sildenafil. Laan et al. ${ }^{[51]}$ examined the effect of a single oral dose of sildenafil on vaginal vasocongestion and subjective sexual arousal in healthy premenopausal women or matching placebo in the first session and the alternate medication in the second session. Significant increase in vaginal vasocongestion was found with sildenafil treatment compared with the placebo with no differences on subjective sexual arousal. Significantly stronger sexual arousal and vaginal wetness were reported for sildenafil versus placebo, indicating that sildenafil was effective in enhancing vaginal engorgement during erotic conditions in healthy women without sexual dysfunction but was not associated with an effect on subjective sexual arousal.

Ashton and Weinstein ${ }^{[52]}$ reported that three women had derived benefit from using $20 \mathrm{mg}$ tadalafil before anticipated sexual activity to reverse medication-induced sexual dysfunction. Angulo et al. ${ }^{[52]}$ evaluated the effects of vardenafil on inhibition of genital vascular responses induced by antidepressants in female rabbits. Potentiation of NO pathway by vardenafil improved vascular sexual responses in female rabbits and overcomes the inhibitory effects of acutely administered antidepressants on genital vascular responses, irrespective of the underlying pathophysiologic mechanism of disruption of the NO pathway or enhancement of $\alpha$-adrenergic mechanisms.

Nurnberg et al. ${ }^{[53]}$ evaluated the efficacy of sildenafil for FSD associated with selective and nonselective antidepressants in women who were randomly assigned to take sildenafil or placebo at a flexible dose starting at $50 \mathrm{mg}$ adjustable to $100 \mathrm{mg}$ before sexual activity with a mean Clinical Global Impression-sexual function score of 1.9 compared with those on placebo with a mean end point difference of 0.8. Assigning baseline values carried forward to the $22 \%$ of patients who prematurely discontinued resulted in a mean end point in the sexual function score of 1.5 among women on sildenafil compared with 0.9 on placebo with a mean end point difference of 0.6.

In addition, it was hypothesized that polymorphisms 
in the androgen receptor gene, encoded by the nucleotides cysteine, adenine, and guanine, influence the effect of testosterone on sexual functioning. In their studies, van Rooij et al. ${ }^{[54,55]}$ investigated the effects of sublingual testosterone combined with a serotonin $1 \mathrm{~A}$ receptor agonist buspirone, and of sublingual testosterone combined with sildenafil $(50 \mathrm{mg})$ on sexual function in premenopausal and postmenopausal women with SSRIs-induced FSD. Women on low dose and having relatively long cysteine, adenine, and guanine repeats reported marked improvement in sexual function in response to both treatments compared with placebo.

\section{Affected relationship}

Women's quality of sexual life is strongly impaired by male ED. After treatment with sildenafil versus untreated patients, the quality of partnership reported by both men and their female partners is significantly better in appropriately treated ED patients than untreated controls $^{[56]}$. After treating male ED, Cayan et al. ${ }^{[57]}$ observed significant improvement in sexual arousal, lubrication, orgasm, satisfaction, and pain in the women suggesting that female sexual function is affected by male erection status and its improvement after treatment. Moreover, Goldstein et al. ${ }^{[58]}$ showed that vardenafil significantly increased total female sexual function index and sexual desire, subjective arousal, lubrication, orgasm and satisfaction domains after treatment-related improvement in erectile function of their male partners.

Conaglen and Conaglen ${ }^{[59]}$ investigated the treatment preference of women whose partners use oral ED medications. A total of $79.2 \%$ of the women preferred their partners' use of tadalafil, whereas $15.6 \%$ preferred sildenafil, which was not affected by age or treatment order randomization. Women preferring tadalafil reported feeling more relaxed, experiencing less pressure, and enjoying a more natural or spontaneous sexual experience, whereas those preferring sildenafil focused on satisfaction and drug effectiveness for their partner.

Chevret-Méasson et al. ${ }^{[60]}$ assessed the effect of ED treatment on female partners using the Index of Sexual Life (ISL), specific of the quality of sexual life of women with ED partners. The ISL sexual life satisfaction score was low at baseline and increased after treatment. The final ISL sexual life satisfaction score was dependent on women's age and final international index of erectile function scores. It is concluded that women satisfaction with their sex life was improved by ED treatment. Martín-Morales et al. ${ }^{[61]}$ showed that vardenafil treatment of men with ED improved both their erectile function and the sexual quality of life of their female partners.

\section{Gynecological implications}

\section{Endometrial thickness}

Vaginal sildenafil has been shown to be useful in increasing endometrial thickness and achieving pregnancy in women with varied uterine disorders. Sher et al. ${ }^{[62]}$ assessed the effects of sildenafil vaginal suppositories (25 mg, four times/day) for 3-10 days on endometrial thickness and in-vitro fertilization (IVF) outcome in infertile women younger than 40 years with poor endometrial development. Vaginal sildenafil showed enhanced endometrial development in $70 \%$ of patients with high implantation and ongoing pregnancy rates. Zinger et al. ${ }^{[63]}$ had successfully managed two women having inadequate endometrium after surgical resection of uterine synechiae with a history of a postpartum uterine curettage with subsequent secondary infertility. Postoperatively, both patients had thin endometrium and failed to conceive despite fertility treatment. These women achieved pregnancy in the first treatment cycle with vaginal sildenafil with improved endometrial thickness. Takasaki et al. ${ }^{[64]}$ showed that sildenafil improves uterine radial artery-resistance index being useful for patients with thin endometrium. Dehghani Firouzabadi et al. ${ }^{[65]}$ pointed out that oral sildenafil is a good way to improve the endometrial receptivity recommending its routine use in patients with previous failure of assisted reproduction technology cycles owing to poor endometrial thickness. Malinova et al. ${ }^{[66]}$ showed the role of sildenafil and serophene on endometrial thickness and volume, endometrial flow index and vascularization flow index, resistivity index (RI) and PI to uterine artery on the day of human chorionic gonadotropin, in prediction of intrauterine insemination outcome in anovulatory women. In sildenafil plus serophene group, the patients got $25 \mathrm{mg}$ sildenafil vaginally and serophene 100-150 mg orally, and in serophene group, $100-150 \mathrm{mg}$ of serophene orally. The mean endometrial thickness and endometrial volume was 11.8 versus 10.2 and 5.2 versus 3.6 respectively with significant decrease in PI and RI to uterine artery in group I. In addition, Soliman et al. ${ }^{[67]}$ assessed in-situ thermosensitive gels for the vaginal administration of sildenafil as a potential treatment of endometrial thinning as a result of using clomiphene citrate for ovulation induction in women with type II eugonadotrophic anovulation. In-situ sildenafil vaginal gel was shown to significantly increase endometrial thickness and uterine blood flow.

\section{Abortion}

Recurrent pregnancy losses are common women's health issue associated with inflammatory and thrombotic events including excessive production of cytokines, in particular tumor necrosis factor- $\alpha$ (TNF- $\alpha$ ). Jerzak et al. ${ }^{[68]}$ assessed the effect of sildenafil on peripheral natural killer cell activity in women with a history of recurrent miscarriage. The natural killer-cell activity was significantly decreased after vaginal sildenafil therapy and their endometrial thickness was significantly increased. El-Far et $a l .{ }^{[69]}$ presented vaginal sildenafil as a safe antiabortive option in treating threatened miscarriage that reduces vasoconstriction by increasing blood flow through relaxation of uterine arteries as indicated from measured PI in unexplained recurrent spontaneous miscarriage cases. Sildenafil was shown to improve the measured antioxidants and improved oxidative stress close to concentrations seen in women in their first trimester of pregnancy. 
Ohams et al. ${ }^{[70]}$ showed treating recurrent abortion with either PDE5 or TNF- $\alpha$ blocker before conception is a promising therapy of immune-dependent recurrent miscarriages, limiting the teratogenic influence of the drugs on the fetus. Luna et al. ${ }^{[71]}$ showed that combined sildenafil plus heparin therapy was superior to either treatment alone for impending pregnancy loss or prophylactically in recurrent miscarriages. Bolnick et al. ${ }^{[72]}$ showed that human first-trimester trophoblast cells proliferate at low $\mathrm{O} 2$, but its survival is compromised by oxidative stress, leading to uteroplacental insufficiency and recurrent pregnancy loss that was optimally inhibited by sildenafil. Bolnick et al. ${ }^{[73]}$ added that sildenafil directly stimulated favorable trophoblast extravillous differentiation for implantation and reduces adverse pregnancy outcome. Luna et al. ${ }^{[74]}$ evaluated the protective effect of sildenafil and dalteparin in a mouse model of Lipopolysaccharideinduced abortion showing that sildenafil either alone or combined with heparin showed the best response. Jerzak et $a l .{ }^{[75]}$ reported a patient with history of four recurrent pregnancy losses and IVF failures that used addition of intralipid to sildenafil and enoxaparin immunotherapy giving birth to a healthy male baby in the third IVF cycle.

\section{Pre-eclampsia}

Pre-eclampsia, the development of new-onset hypertension and proteinuria during pregnancy, affects $3-8 \%$ of all pregnancies and is characterized by systemic endothelial dysfunction. It is responsible for the majority of maternal and perinatal morbidity and mortality associated with complicated pregnancies owing to associated increased uterine artery resistance. Karasu et al. ${ }^{[76]}$ assessed the effects of sildenafil and vardenafil in human umbilical artery preparations taken from pregnant women with pre-eclampsia and healthy pregnant women. Relaxation responses of sildenafil and vardenafil in the presence/absence of NOS and sGC inhibitors were compared. Sildenafil and vardenafilinduced relaxation responses were significantly attenuated in the presence of preeclampsia. In all experiments, a maximal relaxation response was achieved by vardenafil unlike sildenafil. Vardenafil seemed to affect vascular responsiveness of human umbilical artery through the involvement of NO/cGMP-dependent and independent pathways whereas sildenafil-induced responses seemed to be completely NO/cGMP-dependent. In their study, Karasu et $a{ }^{\left[{ }^{[77]}\right.}$ clarified that sildenafil-induced relaxation responses were significantly attenuated in the presence of preeclampsia but not totally abolished indicating that sildenafil might affect vascular responsiveness of human umbilical artery through the involvement of NO/cGMPdependent and NO/cGMP-independent pathways.

Herraiz et al..$^{[78]}$ showed that sildenafil reverses the maternal effects of preeclampsia and improves uteroplacental/fetal perfusion. George et al. ${ }^{[79]}$ showed that sildenafil provides an effective option for managing hypertension during preeclampsia by improving uteroplacental function. Trapani et al. ${ }^{[80]}$ assessed whether oral sildenafil prolongs gestation in singleton pregnancies with pre-eclampsia between 24 and 33 weeks of gestation randomized to $50 \mathrm{mg}$ sildenafil $/ 8 \mathrm{~h}$ or placebo. Pregnancy duration was on average 4 days longer, and the reduction in PI of both uterine and umbilical arteries was higher for patients on sildenafil compared with placebo.

Gillis et al. ${ }^{[81]}$ hypothesized that sildenafil would improve the maternal syndrome and fetal outcome in a rat model of superimposed preeclampsia on oral sildenafil ( $50 \mathrm{mg} / \mathrm{kg} /$ day $)$ from day 10 through day 20 of pregnancy. Untreated rats had a significant rise in blood pressure and a 2-fold increase in urinary protein excretion from baseline to late pregnancy. However, sildenafiltreated rats exhibited $\approx 40 \mathrm{mmHg}$ drop in the blood pressure with no rise in protein excretion. Sildenafil also increased creatinine clearance, reduced uterine artery RI during late pregnancy, and improved fetal outcome. In addition, $19 \%$ of all pups showed resorption in untreated rats, with no incidence of resorptions in the treated group. In addition, TNF- $\alpha$, endothelin-1, and oxidative stress, which are increased in experimental models, were reduced in treated rats. Stanley et al. ${ }^{[82]}$ showed that sildenafil rescues the dysfunction in uterine arteries of women with preeclampsia by increasing uterine artery vasodilation, thereby decreasing uterine artery resistance and, hence, ameliorated preeclampsia in a mouse model of preeclampsia.

Nevertheless, one of the key molecules implicated in severe preeclampsia pathogenesis is heme oxygenase-1 (HO-1), a rate-limiting enzyme that breaks down heme into carbon monoxide (CO), biliverdin, and free iron ${ }^{[4,83]}$. $\mathrm{CO}$ and bilirubin account for the angiogenic, vasodilatory, and antioxidant properties of HO-1 ${ }^{[84,85]}$. These collective actions of the heme breakdown metabolites generated by HO-1 offer protection against cytotoxicity, inflammation, hypoxia, and other forms of cellular stress ${ }^{[8-89]}$.

\section{Fetal growth restriction}

Fetal growth restriction (FGR) is the inability of a fetus to achieve its genetic growth potential. It affects up to $8 \%$ of all pregnancies and has both massive shortterm (increased fetal morbidity and mortality) and longterm (increased incidence of cardiovascular disease in adulthood) health implications. Wareing et al. ${ }^{[90]}$ showed that sildenafil improves endothelial function of myometrial vessels from women whose pregnancies are complicated by intrauterine FGR. von Dadelszen et al. ${ }^{[91]}$ offered sildenafil (25 $\mathrm{mg}$ three times a day until delivery) for women if their pregnancy was complicated by early-onset FGR and either the gestational age younger than 25 weeks or an estimate of the fetal weight of less than $600 \mathrm{~g}$. Sildenafil treatment was associated with increased fetal abdominal circumference growth compared with institutional sildenafil-naive earlyonset FGR controls. 
Dastjerdi et al. ${ }^{[92]}$ assessed whether sildenafil affects uteroplacental perfusion in pregnant women with intrauterine FGR at 24-37 weeks of gestation by Doppler ultrasound of the umbilical and middle cerebral arteries. Sildenafil group fetuses showed a significant decrease in systolic/ diastolic ratios and PI of the umbilical artery and a significant increase in the middle cerebral artery PI. They concluded that sildenafil improves fetoplacental perfusion in pregnancies complicated by intrauterine FGR. Dilworth et al. ${ }^{[93]}$ pointed out that sildenafil improves fetal growth even in the absence of abnormal placental blood flow.

\section{Clitoral engorgement}

Alatas et al. ${ }^{[94]}$ determined the effect of sildenafil on the uterine circulation and clitoral artery blood flow in postmenopausal women. After sildenafil intake, the mean RI and PI of uterine artery were significantly lower compared with baseline values, and the mean peak systolic velocity of the clitoral artery was significantly higher. It is concluded that sildenafil improves the clitoral and uterine blood flow in healthy postmenopausal women without erotic stimuli. Cavalcanti et al. ${ }^{[95]}$ assessed the effects of $50-\mathrm{mg}$ dose of sildenafil or placebo daily for 15 days on clitoral blood flow and sexual response in postmenopausal women with orgasmic dysfunction. The Golombok Rust Inventory of Sexual Satisfaction (GRISS) was used for subjective evaluation of the sexual-response cycle, whereas the clitoral blood flow was measured at baseline, after 1 $\mathrm{h}$ of the first dose, and after 15 days of treatment. Blood flow was significantly improved in the sildenafil than the placebo group with a positive correlation between Doppler values and GRISS scores in the sildenafil group after 15 days of treatment.

Yang et al. ${ }^{[96]}$ determined if MRI could quantify a difference in clitoral response following vasoactive medication, in women with FSAD. Sildenafil $50 \mathrm{mg}$ versus placebo were administered $1 \mathrm{~h}$ before genital MRI performed while patients viewed alternating segments of nonerotic and erotic video. The mean change in clitoral volume for the entire group was higher in the sildenafil MRI session compared with the placebo. On the contrary, Leddy et al. ${ }^{[97]}$ concluded that sildenafil did not augment the genital response in women with FSAD, and most women did not have impaired clitoral engorgement, suggesting that FSAD is not predominantly a disorder of genital engorgement.

\section{Primary dysmenorrhea}

Primary dysmenorrhea is a condition that most women have and seek a treatment for.

Dmitrovic et al. ${ }^{[98]}$ compared vaginal preparation of sildenafil (100 mg single dose) with a placebo in patients with primary dysmenorrhea at the time of painful menstruation. At baseline and 1, 2, 3, and $4 \mathrm{~h}$ after treatment, the patients were asked to assess their degree of pain using two scales: pain on the five-level ordinal scale and pain level on the visual analog scale. Sildenafil group had significantly better pain relief compared with the placebo group and provided better pain relief than placebo at each time point. At the 2-h time point, the PI was significantly lower in the sildenafil-treated group compared with the placebo group.

\section{Uterine blood flow}

Hale et al. ${ }^{[99]}$ assessed the effect of sildenafil on uterine volumetric blood flow (UVF) and vascular impedance in nonpregnant, nulliparous women who received placebo or sildenafil (25 or $100 \mathrm{mg}$ ) during the luteal phase of the cycle. Those who received sildenafil had significantly increased UVF and decreased RI over the 3-h monitoring period. When UVF responses to sildenafil were examined as a function of baseline, a significant increase in UVF was observed in those with higher baseline UVF. Overall, women in the luteal phase showed a significant increase in UVF in response to sildenafil. Moreover, Ramesar et al. ${ }^{[100]}$ speculated that sildenafil improves uterine artery blood flow resulting in improved fetal outcome in pregnant rats.

\section{Oligohydramnios}

Maher et al. ${ }^{[101]}$ compared sildenafil $(25 \mathrm{mg} / 8 \mathrm{~h})$ plus hydration with hydration alone in improving the amniotic fluid index and neonatal outcome in pregnancies at more than 30 weeks of gestation complicated by idiopathic oligohydramnios (amniotic fluid index $<5 \mathrm{~cm}$ without maternal or fetal causes and with normal fetal growth). The amniotic fluid volume was higher in the sildenafil group $(11.5$ vs. $5.4 \mathrm{~cm})$, was delivered later (38.3 vs. 36.0 weeks of gestation), had a lower rate of cesarean delivery ( $28 \mathrm{vs.}$ $73 \%$ ), and resulted in neonates less likely to be admitted to the neonatal ICU (11 vs. $41 \%$ ). The authors concluded that sildenafil increases amniotic fluid volume in pregnancies complicated by oligohydramnios.

\section{Poor ovarian response}

The use of sildenafil as an adjunct to controlled ovarian hyperstimulation protocols may enhance ovarian response in women with poor ovarian response. Trakakis et al. ${ }^{[102]}$ presented a case of a pregnancy achieved by administering sildenafil to a 37-year-old woman not responding to controlled ovarian hyperstimulation with the sole use of gonadotropins without follicular growth. Addition of oral sildenafil improved her ovarian response.

\section{Ovarian ischemia/reperfusion}

Arikan et al. ${ }^{[103]}$ showed that tadalafil prevents tissue damage induced by ovarian ischemia/reperfusion (I/R) in rat ovaries. Celik et al. ${ }^{[104]}$ pointed that sildenafil ameliorates antioxidant enzyme activities, lipid peroxidation, and histopathological changes in ovarian tissue after I/R injury in rats. Incebiyik et al. ${ }^{[102]}$ reported the protective activity of sildenafil against $\mathrm{I} / \mathrm{R}$ damage in rat ovaries by decreasing tissue damage and oxidative stress.

\section{Uterine contractility}

Winston et al. ${ }^{[105]}$ showed that sildenafil inhibits the 
contractility of isolated nonpregnant human myometrium by opening Ca-sensitive $\mathrm{K}$ channels.

\section{Urological implications}

\section{Overactive bladder}

Razdorskaia et al. ${ }^{[106]}$ assessed the treatment outcome in women with overactive bladder (OAB) with imperative incontinence and obstructive urination disorders by a combination of alpha1-adrenoblockers (alfuzosin $5 \mathrm{mg}$ at night) and PDE-5 inhibitors (tadalafil $5 \mathrm{mg}$ daily in the morning) for a month. After treatment, the time of urination was reduced; urinary volume and maximum urinary flow rate, as well as cystometric capacity have increased; involuntary detrusor contractions in the bladder filling phase (spontaneous/provoked) became less, or absent; and the residual urine volume has decreased. Laser Doppler flowmetry showed an increase of neurogenic tone in precapillary, bypass coefficient and microcirculation effectiveness index, as well as increase in microcirculation index and the coefficient of variation, indicating improved microcirculation in the bladder mucosa.

Chen et $a l^{[107]}$ assessed the efficacy of daily lowdose 5-mg tadalafil or placebo for 3 months for OAB in women. The OAB symptom score significantly decreased, and the frequency, incontinence, and urgency episodes significantly improved in the tadalafil treatment group compared with the placebo group and baseline at weeks $4,6,8,10,12$, as well as 3 months after treatment. In addition, voided volume and total bladder capacity were increased in the treatment group, whereas the Indevus Urgency Severity Scale was decreased from week 4 to 3 months after treatment in the treatment group.

\section{Interstitial cystitis}

Chen et al. ${ }^{[108]}$ assessed the efficacy of daily low-dose sildenafil $(25 \mathrm{mg})$ for nonulcer interstitial cystitis in women compared with placebo for 3 months. Interstitial cystitis symptom and problem indices scores and urodynamic index were significantly improved in sildenafil-treated group at week 4, 6, 8, 10, and 12, and 3 months after treatment. Urodynamic index including first desire to void, strong desire to void, and maximum cystometric capacity was significantly improved in sildenafil treated group at week 12 and at 3 months after treatment.

\section{Dermatological implications}

\section{Systemic scleroderma}

Alekperov et al. ${ }^{[109]}$ analyzed the efficacy and safety of sildenafil in patients with systemic sclerosis in 14 women with mean duration of 8.8 years. The indications for treatment were significant Raynaud's phenomenon in three patients, digital ulcers (DU) and/or necroses in nine, pulmonary hypertension $(\mathrm{PH})$ in five patients, and critical ischemia of the left fingers in one patient. There was a significant decrease in the frequency and intensity of Raynaud's attacks in 11/15 (73\%) patients treated with sildenafil in the first days and remained stable throughout the treatment. All patients with DUs showed decreased sizes just within the first 2 weeks of treatment. Complete DU healing was observed within 4-12 weeks of treatment. During a month, the necrotic area reduced and the signs of reparation appeared in 4/6 patients. Pain ceased just within the first 5-7 days of treatment. The authors concluded that sildenafil is effective to treat the manifestations of scleroderma vasculopathy, such as Raynaud's phenomenon, DU/necroses, and $\mathrm{PH}$.

\section{Cellulite}

Altabas et al. ${ }^{[110]}$ provided a hypothesis considering the potential effect of PDE5a inhibitors on cellulite, a significant cosmetic problem for many postadolescent women. Its pathophysiology is complex and involves the presence of excess subcutaneous fat, the microcirculatory system, lymphatics, and the extracellular matrix. Many treatments were tested like iontophoresis, ultrasound, thermotherapy, pressotherapy, lymphatic drainage, and electrolipophoresis to enhance skin microcirculation. Human fat cell lipolysis is mediated by both cAMP-dependent and cGMP-dependent protein kinases. High-dose sildenafil pretreatment leads to increased lipolysis in adipocyte cultures. This effect could not be attributed exclusively to either PDE3b or PDE5a inhibition, as sildenafil inhibited $\sim 50 \%$ of the PDE3b activity in pretreated adipocytes. Sildenafil was shown to have a potential beneficial effect on skin microcirculation and tissue hypoxia. The authors concluded that transdermal or local route of administration should be considered.

\section{Other implications}

\section{Pulmonary arterial hypertension}

Pulmonary arterial hypertension (PAH) is a rare condition characterized by sustained elevation in pulmonary arterial resistance leading to right heart failure. PAH afflicts predominantly women. Conventional treatment includes nonspecific drugs (warfarin, diuretics, and oxygen). The endothelin-1 receptor antagonists bosentan, sildenafil, and prostanoids have been shown to improve symptoms, exercise capacity, and hemodynamics. However, intravenous prostacyclin is the first-line treatment for the most severely affected patients ${ }^{[111}$. Jiménez López-Guarch et al. ${ }^{[112]}$ showed that the addition of oral sildenafil to chronic prostacyclin treatment in patients with severe $\mathrm{PH}$ improves functional capacity and reduces episodes of decompensated right heart failure, with nonsignificant adverse effects. Michelakis et al. ${ }^{[113]}$ showed that sildenafil may be superior to iNO in that it increases cardiac output and does not increase wedge pressure. Gomberg-Maitland et al. ${ }^{[14]}$ showed that subcutaneous treprostinil with sildenafil for PAH has additive beneficial effects. Milman et al. ${ }^{[115]}$ showed that patients with severe pulmonary sarcoidosis have a high prevalence of $\mathrm{PH}$, whereas sildenafil treatment was associated with significant improvements in hemodynamic parameters.

Olfert et al. ${ }^{[116]}$ showed that sildenafil and bosentan equally improve arterial oxygenation in acute hypoxia, 
which could account for improved physical performance at altitude. Watanabe et al. ${ }^{[117]}$ concluded that sildenafil may improve dyspnea, exercise tolerance, and healthrelated quality of life in some patients with $\mathrm{PH}$. Lopez-Meseguer et al. ${ }^{[118]}$ suggested that therapy with inhaled iloprost-silenafil represents an acceptable alternative in patients with severe and unstable PAH.

Huang and DeSantis ${ }^{[119]}$ described the successful treatment with sildenafil, a pregnancy category B drug, in pregnant patients with PAH. Sun et al. ${ }^{[120]}$ explored the effect of sildenafil in treatment of pregnant women with PAH. Sildenafil can significantly improve the clinical symptoms, cardiac function, hemodynamics, pregnancy outcome, reduce premature delivery, the incidence of low-birth-weight children, and cesarean section rate. Cartago et al $^{[121]}$ reported three cases of PAH in pregnancy treated with sildenafil combined with another drug. Treatment for PAH using sildenafil as monotherapy may allow stabilization of the maternal condition and improve clinical outcomes for both mother and baby.

Volkov et al. ${ }^{[122]}$ assessed the effect of sildenafil 20 mg three times a day on the survival of patients with $\mathrm{PAH}$ associated with connective tissue diseases in women corresponded to functional class II. Three-year survival rates were $94 \%$ in the study group and $25 \%$ in controls. Rusiecki et al. ${ }^{[123]}$ assessed treatment response by examining change in 6-min walk distance (6MWD) and time to clinical worsening with the effect of menopausal status on the same treatment measures before and after 16 weeks of treatment with tadalafil or placebo. For tadalafiltreated patients, a significant difference was shown in 6MWD with a mean $34.7 \mathrm{~m}$ for females. There was a trend toward a female age-dependent effect in change in 6MWD; the premenopausal group showed the greatest improvement. This trial suggested that premenopausal women may experience functional improvement when treated with tadalafil than older women.

\section{Coronary dysfunction}

Microvascular coronary dysfunction is associated with symptoms and signs of ischemia, and also adverse outcomes in women without macrovascular obstructive coronary artery disease (M-CAD). For women with symptoms and signs of ischemia and no M-CAD, PDE-5 inhibition is associated with acute improvement in coronary flow reserve, and the effect concentrates among those with coronary flow reserve of up to 2.5. If these acute effects are sustained, then PDE-5 inhibition would provide a rational strategy for management of microvascular coronary dysfunction in symptomatic women without M-CAD ${ }^{[124]}$.

\section{Esophageal motility}

In 16 normal individuals (nine men and seven women), esophageal motility was recorded. After a basal period of $60 \mathrm{~min}$, a tablet of sildenafil 50-mg ground and dissolved in water was infused in the stomach in eight individuals and a placebo tablet in the other eight individuals; the recording continued for $60 \mathrm{~min}$. Sildenafil was shown to induce significant decrease of lower esophageal sphincter tone, residual pressure, wave amplitude, and propagation velocity and a significant increase of onset latency of pressure waves compared with the values of the basal period and placebo. The inhibitory effect reached its maximum 10-15 min after the infusion and lasted about $1 \mathrm{~h}^{[125]}$.

\section{Metabolic effects}

It is suggested that reduced synthesis of NO in endothelial cells, that is endothelial dysfunction, contributes to the impaired action of insulin in the vasculature of patients with type 2 diabetes. Jansson et al. ${ }^{[126]}$ assessed whether selective inhibition of PDE- 5 by tadalafil has beneficial metabolic effects on peripheral microcirculation and glucose uptake. In women with type 2 diabetes, but not in the controls, tadalafil induced increases in the permeability surface area for glucose and forearm glucose uptake. However, fasting glucose and insulin concentrations were similar following treatment with placebo or tadalafil in the two groups. This study suggests that tadalafil evokes positive metabolic effects in insulin-resistant women with type 2 diabetes. Murdolo et al..$^{[27]}$ explored the acute in-vivo effects of tadalafil on local microcirculation and regional metabolism in skeletal muscle and adipose tissue. Tadalafil emerges as an acutely acting modulator of microvascular recruitment and glucose metabolism in skeletal muscle and adipose tissue.

\section{CONCLUSION}

PDE5 inhibitors as an effective and beneficial molecules have their potential implications in women, which could be considered as additional accomplishment. However, preclinical as well as pharmacological studies should be thoroughly searched for before establishing its uses.

\section{CONFLICTS OF INTEREST}

There are no conflicts of interest.

\section{REFERENCES}

1. Panach-Navarrete J, Morales-Giraldo A, FerrandisCortés C, García-Morata F, Pastor-Lence JC, Martínez-Jabaloyas JM. Satisfaction and treatment adherence in erectile dysfunction in the medium and long term. Actas Urol Esp 2017; 41:258-266.

2. Hassan A, El-Hadidy M, El-Deeck BS, Mostafa T. Couple satisfaction to different therapeutic modalities for organic erectile dysfunction. J Sex Med 2008; 5:2381-2391.

3. El-Meliegy A, Rabah D, Al-Mitwalli K, Mostafa $\mathrm{T}$, Hussein $\mathrm{T}$, Istarabadi $\mathrm{M}$, et al. A 6-month, prospective, observational study of PDE5 inhibitor treatment persistence and adherence in Middle Eastern and North African men with erectile dysfunction. Curr Med Res Opin 2013; 
29:707-717.

4. Abdel Aziz MT, El-Asmer MF, Mostafa T, Mostafa S, Atta H, Aziz Wassef MA, et al. Heme oxygenase vs. nitric oxide synthase in signaling mediating sildenafil citrate action. J Sex Med 2007; 4:1098-1107.

5. El-Metwally MA, Sharabi FM, Daabees TT, Senbel AM, Mostafa T. Involvement of alpha-receptors and potassium channels in the mechanism of action of sildenafil citrate. Int J Impot Res 2007; 19:551-557.

6. Mostafa T, Rashed L, Kotb K, Taymour M. Effect of testosterone and frequent low-dose sildenafil/ tadalafil on cavernous tissue oxidative stress of aged diabetic rats. Andrologia 2012; 44:411-415.

7. Mostafa T, Sabry D, Abdelaal AM, Mostafa I, Taymour M. Cavernous antioxidant effect of green tea, epigallocatechin-3-gallate with/without sildenafil citrate intake in aged diabetic rats. Andrologia 2013; 45:272-277.

8. Mostafa T, Rashed LA, Kotb K. Testosterone and chronic sildenafil/tadalafil anti-apoptotic role in aged diabetic rats. Int J Impot Res 2010; 22:255261.

9. Langtry HD, Markham A. Sildenafil: a review of its use in erectile dysfunction. Drugs 1999; 57:967-989.

10. Sommer F, Engelmann U. Vardenafil Bayer Yakuhin. Curr Opin Investig Drugs 2002; 3:607-613.

11. Bella AJ, Brock GB. Tadalafil in the treatment of erectile dysfunction. Curr Urol Rep 2003; 4:472-478.

12. Mostafa ME, Senbel AM, Mostafa T. Effect of chronic low-dose tadalafil on penile cavernous tissues in diabetic rats. Urology 2013; 81:1253-9125.

13. Burke RM, Evans JD. Avanafil for treatment of erectile dysfunction: review of its potential. Vasc Health Risk Manag 2012; 8:517-523.

14. Mostafa T. Oral phosphodiesterase type 5 inhibitors: nonerectogenic beneficial uses. J Sex Med 2008; 5:2502-2518.

15. Mostafa T. Useful implications of low-dose longterm use of PDE-5 inhibitors. Sex Med Rev 2016; $4: 270-284$.

16. Mostafa T. Non-sexual implications of phosphodiesterase type 5 inhibitors. Sex Med Rev 2017; 5:170-199.

17. Mostafa T. In vitro sildenafil citrate use as a sperm motility stimulant. Fertil Steril 2007; 88:994-996.

18. Mostafa T. Tadalafil as an in vitro sperm motility stimulant. Andrologia 2007; 39:12-15.
19. Walton B, Thorton T. Female sexual dysfunction. Curr Womens Health Rep 2003; 3:319-326.

20. Jayne CJ, Heard MJ, Zubair S, Johnson DL. New developments in the treatment of hypoactive sexual desire disorder: a focus on Flibanserin. Int $\mathrm{J}$ Womens Health 2017; 9:171-178.

21. Gelman F, Atrio J. Flibanserin for hypoactive sexual desire disorder: place in therapy. Ther Adv Chronic Dis 2017; 8:16-25.

22. Chivers M, Rosen RC. Phosphodiesterase type 5 inhibitors and female sexual response: faulty protocols or paradigms? J Sex Med 2010; 7:858-872.

23. Caruso S, Intelisano G, Lupo L, Agnello C. Premenopausal women affected by sexual arousal disorder treated with sildenafil: a double-blind, cross-over, placebo-controlled study. BJOG 2001; 108:623-628.

24. Caruso S, Intelisano G, Farina M, Di Mari L, Agnello C. The function of sildenafil on female sexual pathways: a double-blind, cross-over, placebo-controlled study. Eur J Obstet Gynecol Reprod Biol 2003; 110:201-206.

25. Dasgupta R, Wiseman OJ, Kanabar G, Fowler CJ, Mikol D. Efficacy of sildenafil in the treatment of female sexual dysfunction due to multiple sclerosis. J Urol 2004; 171:1189-1193.

26. Ferrara D, Zaslau S. Success of sildenafil treatment in neurogenic female sexual dysfunction caused by L5-S1 intervertebral disk rupture: a case report. Int J Urol. 2007; 14:566-567.

27. Snoeren EM, Bovens A, Refsgaard LK, Westphal $\mathrm{KG}$, Waldinger MD, Olivier B, Oosting RS. Combination of testosterone and vardenafil increases female sexual functioning in sub-primed rats. J Sex Med 2011; 8:989-1001.

28. van der Made F, Bloemers J, van Ham D, El Yassem W, Kleiverda G, Everaerd W, et al. Childhood sexual abuse, selective attention for sexual cues and the effects of testosterone with or without vardenafil on physiological sexual arousal in women with sexual dysfunction: a pilot study. J Sex Med 2009; 6:429-439.

29. van der Made F, Bloemers J, Yassem WE, Kleiverda G, Everaerd W, van Ham D, et al. The influence of testosterone combined with a PDE5inhibitor on cognitive, affective, and physiological sexual functioning in women suffering from sexual dysfunction. J Sex Med 2009; 6:777-790.

30. Zeinalzadeh S, Akbarzadeh M, Mohagheghzadeh A, Faridi P, Sayadi M. Comparison of the effects of Elaeagnus angustifolia flower capsule and sildenafilsildenafil tablet on anxiety resulting 
from sexual dysfunction in women referring to the selected clinics of Shiraz University of Medical Sciences. J Evid Based Complementary Altern Med 2016; 21:186-193.

31. Poels S, Bloemers J, van Rooij K, Goldstein I, Gerritsen J, van Ham D, et al. Toward personalized sexual medicine (part 2): testosterone combined with a PDE5 inhibitor increases sexual satisfaction in women with HSDD and FSAD, and a low sensitive system for sexual cues. J Sex Med 2013; $10: 810-823$.

32. Poels S, Bloemers J, van Rooij K, Koppeschaar $\mathrm{H}$, Olivier B, Tuiten A. Two novel combined drug treatments for women with hypoactive sexual desire disorder. Pharmacol Biochem Behav 2014; 121:71-79.

33. Akbarzadeh M, Zeinalzadeh S, Zolghadri J, Mohagheghzadeh A, Faridi P, Sayadi M. Comparison of Elaeagnus angustifolia extract and sildenafil on female orgasmic disorders: a randomized clinical trial. J Reprod Infertil 2014; 15:190-198.

34. Borghi C, Dell'Atti L. Tadalafil once daily: narrative review of a treatment option for female sexual dysfunctions (FSD) in midlife and older women. Arch Ital Urol Androl 2017; 89:7-11.

35. Alp HH, Huyut Z, Yildirim S, Başbugan Y, Ediz L, Şekeroğlu MR. The effect of PDE5 inhibitors on bone and oxidative damage in ovariectomyinduced osteoporosis. Exp Biol Med (Maywood) 2017: 242:1051-1061.

36. Schoen C, Bachmann G. Sildenafil citrate for female sexual arousal disorder: a future possibility?. Nat Rev Urol 2009; 6:216-222.

37. Lo Monte G, Graziano A, Piva I, Marci R. Women taking the 'blue pill' (sildenafil citrate): such a big deal? Drug Des Devel Ther 2014; 8:2251-2254.

38. D'Amati G, di Gioia CR, Bologna M, Giordano D, Giorgi M, Dolci S, Jannini EA. Type 5 phosphodiesterase expression in the human vagina. Urology 2002; 60:191-195.

39. Oelke M, Hedlund $P$, Albrecht K, Ellinghaus $P$, Stief $\mathrm{CG}$, Jonas U, et al. Expression of cAMP and cGMP phosphodiesterase isoenzymes 3,4 , and 5 in the human clitoris: immunohistochemical and molecular biology study. Urology 2006; 67:1111-1116.

40. Uckert S, Ellinghaus $\mathrm{P}$, Albrecht $\mathrm{K}$, Jonas U, Oelke M. expression of messenger ribonucleic acid encoding for phosphodiesterase isoenzymes in human female genital tissues. J Sex Med 2007; 4:1604-1609.
41. Berman JR, Berman LA, Lin H, Flaherty E, Lahey N, Goldstein I, Cantey-Kiser J. Effect of sildenafil on subjective and physiologic parameters of the female sexual response in women with sexual arousal disorder. J Sex Marital Ther 2001; 27:411-420.

42. Sipski ML, Rosen RC, Alexander CJ, Hamer RM. sildenafil effects on sexual and cardiovascular responses in women with spinal cord injury. Urology 2000; 55:812-815.

43. Caruso S, Rugolo S, Agnello C, Intelisano G, Di Mari L, Cianci A. Sildenafil improves sexual functioning in premenopausal women with type 1 diabetes who are affected by sexual arousal disorder: a double-blind, crossover, placebo-controlled pilot study. Fertil Steril 2006; 85:1496-1501.

44. Berman JR, Berman LA, Toler SM, Gill J, Haughie S, Sildenafil Study Group. Safety and efficacy of sildenafil citrate for the treatment of female sexual arousal disorder: a doubleblind, placebo controlled study. J Urol 2003; 170:2333-2338.

45. Claret L, Cox EH, McFadyen L, Pidgen A, Johnson PJ, Haughie S, et al. Modeling and simulation of sexual activity daily diary data of patients with female sexual arousal disorder treated with sildenafil citrate (Viagra). Pharm Res 2006; 23:1756-1764.

46. Alexander MS, Rosen RC, Steinberg S, Symonds T, Haughie S, Hultling C. Sildenafil in women with sexual arousal disorder following spinal cord injury. Spinal Cord 2011; 49:273-279.

47. Omidi A, Ahmadvand A, Najarzadegan MR, Mehrzad F. Comparing the effects of treatment with sildenafil and cognitive-behavioral therapy on treatment of sexual dysfunction in women: a randomized controlled clinical trial. Electron Physician 2016; 8:2315-2324.

48. Caruso S, Cicero C, Romano M, Lo Presti L, Ventura B, Malandrino C. Tadalafil $5 \mathrm{mg}$ daily treatment for type 1 diabetic premenopausal women affected by sexual genital arousal disorder. J Sex Med 2012; 9:2057-2065.

49. Fava M, Rankin MA, Alpert JE, Nierenberg AA, Worthington JJ. An open trial of oral sildenafilin antidepressant-induced sexual dysfunction. Psychother Psychosom 1998;67:328-331.

50. Nurnberg HG, Hensley PL, Lauriello J, Parker LM, Keith SJ. Sildenafil for women patients with antidepressant-induced sexual dysfunction. Psychiatr Serv 1999; 50:1076-1078.

51. Laan E, van Lunsen RH, Everaerd W, Riley 
A, Scott E, Boolell M. The enhancement of vaginal vasocongestion by sildenafil in healthy premenopausal women. J Womens Health Gend Based Med 2002; 11:357-365.

52. Ashton AK, Weinstein W. Tadalafil reversal of sexual dysfunction caused by serotonin enhancing medications in women. J Sex Marital Ther 2006; $32: 1-3$.

53. Angulo J, Cuevas P, Cuevas B, Bischoff E, de Tejada IS. Antidepressant-induced inhibition of genital vascular responses is reversed by vardenafil in female rabbits. J Sex Med 2006; 3:988-995.

54. Nurnberg HG, Hensley PL, Heiman JR, Croft HA, Debattista C, Paine S. Sildenafil treatment of women with antidepressant-associated sexual dysfunction: a randomized controlled trial. JAMA 2008; 300:395-404.

55. van Rooij K, Poels S, Bloemers J, Goldstein I, Gerritsen J, vanHamD, et al. Toward personalized sexual medicine (part 3): testosterone combined with a Serotonin1A receptor agonist increases sexual satisfaction in women with HSDD and FSAD, and dysfunctional activation of sexual inhibitory mechanisms. J Sex Med 2013; 10:824-837.

56. van Rooij K, Poels S, Worst P, Bloemers J, Koppeschaar H, Goldstein A, et al. Efficacy of testosterone combined with a PDE5 inhibitor and testosterone combined with a serotonin (1A) receptor agonist in women with SSRI-induced sexual dysfunction. A preliminary study. Eur J Pharmacol 2015; 753:246-251.

57. Müller MJ, Ruof J, Graf-Morgenstern M, Porst $\mathrm{H}$, Benkert O. Quality of partnership in patients with erectile dysfunction after sildenafil treatment. Pharmacopsychiatry 2001; 34:91-95.

58. Cayan S, Bozlu M, Canpolat B, Akbay E. The assessment of sexual functions in women with male partners complaining of erectile dysfunction: does treatment of male sexual dysfunction improve female partner's sexual functions? J Sex Marital Ther 2004; 30:333-341.

59. Goldstein I, Fisher WA, Sand M, Rosen RC, Mollen M, Brock G, et al., Vardenafil Study Group. Women's sexual function improves when partners are administered vardenafil for erectile dysfunction: a prospective, randomized, doubleblind, placebo-controlled trial. J Sex Med 2005; 2:819-832.

60. Conaglen HM, Conaglen JV. Investigating women's preference for sildenafil or tadalafil use by their partners with erectile dysfunction: the partners' preference study. J Sex Med 2008; 5:1198-1207.

61. Chevret-Méasson M, Lavallée E, Troy S, Arnould B, Oudin S, Cuzin B. Improvement in quality of sexual life in female partners of men with erectile dysfunction treated with sildenafil citrate: findings of the Index of Sexual Life (ISL) in a couple study. J Sex Med 2009; 6:761-769.

62. Martín-Morales A, Graziottin A, Jaoudé GB, Debruyne F, Buvat J, Beneke M, Neuser D. Improvement in sexual quality of life of the female partner following vardenafil treatment of men with erectile dysfunction: a randomized, doubleblind, placebo-controlled study. J Sex Med 2011; 8:2831-2840.

63. Sher G, Fisch JD. Effect of vaginal sildenafil on the outcome of in vitro fertilization (IVF) after multiple IVF failures attributed to poor endometrial development. Fertil Steril 2002; 78:1073-1076.

64. Zinger M, Liu JH, Thomas MA. Successful use of vaginal sildenafil citrate in two infertility patients with Asherman's syndrome. J Womens Health (Larchmt) 2006; 15:442-444.

65. Takasaki A, Tamura H, Miwa I, Taketani T, Shimamura K, Sugino N. Endometrial growth and uterine blood flow: a pilot study for improving endometrial thickness in the patients with a thin endometrium. Fertil Steril 2010; 93:1851-1858.

66. Dehghani Firouzabadi R, Davar R, Hojjat F, Mahdavi M. Effect of sildenafil citrate on endometrial preparation and outcome of frozenthawed embryo transfer cycles: a randomized clinical trial. Sildenafil may increase endometrial thickness and affect the outcome of frozen-thawed embryo transfer cycles. Iran J Reprod Med 2013; 11:151-158.

67. Malinova M, Abouyta T, Krasteva M. The effect of vaginal sildenafil citrate on uterine blood flow and endometrium in the infertile women. Akush Ginekol (Sofiia) 2013; 52:26-30.

68. Soliman GM, Fetih G, Abbas AM. Thermosensitive bioadhesive gels for the vaginal delivery of sildenafil: in vitro characterization and clinical evaluation in women using clomiphene for induction of ovulation. Drug Dev Ind Pharm 2017; 43:399-408.

69. Jerzak M, Kniotek M, Mrozek J, Górski A, Baranowski W. Sildenafil citrate decreased natural killer cell activity and enhanced chance of successful pregnancy in women with a history 
of recurrent miscarriage. Fertil Steril 2008; 90:1848-1853.

70. El-Far M, El-Motwally Ael-G, Hashem IA, Bakry $\mathrm{N}$. Biochemical role of intravaginal sildenafil citrate as a novel antiabortive agent in unexplained recurrent spontaneous miscarriage: first clinical study of four case reports from Egypt. Clin Chem Lab Med 2009; 47:1433-1438.

71. Ohams M, Jerzak M, Górski A. Effects of sildenafil citrate and etanercept treatment on TNF- $\alpha$ levels in peripheral blood of women with recurrent miscarriage. Ginekol Pol 2015; 86:520-524.

72. Luna RL, Nunes AK, Oliveira AG, Araujo SM, Lemos AJ, Rocha SW, et al. Sildenafil (Viagra) blocks inflammatory injury in LPS-induced mouse abortion: a potential prophylactic treatment against acute pregnancy loss? Placenta 2015; $36: 1122-1129$.

73. Bolnick JM, Kilburn BA, Bolnick AD, Diamond MP, Singh M, Hertz M, et al. Sildenafil stimulates human trophoblast invasion through nitric oxide and guanosine 3',5'-cyclic monophosphate signaling. Fertil Steril 2015; 103:1587-1595.

74. Bolnick JM, Kilburn BA, Bolnick AD, Diamond MP, Singh M, Hertz M, et al. Sildenafil prevents apoptosis of human first-trimester trophoblast cells exposed to oxidative stress: possible role for nitric oxide activation of 3',5'-cyclic guanosine monophosphate signaling. Reprod Sci 2015; 22:718-724.

75. Luna RL, Vasconcelos AG, Nunes AK, de Oliveira WH, Barbosa KP, Peixoto CA. effects of sildenafil citrate and heparin treatments on placental cell morphology in a murine model of pregnancy loss. Cells Tissues Organs 2016; 201:193-202.

76. Jerzak M, Szafarowska M, Kniotek M, Gorski A. Successful pregnancy after Intralipid addition to sildenafil and enoxaparin in woman with history of recurrent pregnancy loss (RPL). Neuro Endocrinol Lett 2016; 37:473-477.

77. Karasu E, Kayacan N, Sadan G, Dinc B. Different effects of different phosphodiesterase type-5 inhibitors in pre-eclampsia. Pregnancy Hypertens 2011; 1:231-237.

78. Karasu E, Kayacan N, Sadan G, Dinc B. Endothelial dysfunction in the human umbilical artery due to preeclampsia can be prevented by sildenafil. Clin Exp Hypertens 2012; 34:79-85.

79. Herraiz S, Pellicer B, Serra V, Cauli O, Cortijo J, Felipo V, Pellicer A. Sildenafil citrate improves perinatal outcome in fetuses from pre-eclamptic rats. BJOG 2012; 119:1394-1402.

80. George EM, Palei AC, Dent EA, Granger JP.
Sildenafil attenuates placental ischemia-induced hypertension. Am J Physiol Regul Integr Comp Physiol 2013; 305:R397-R403.

81. Trapani A Jr, Gonçalves LF, Trapani TF, Vieira S, Pires M, Pires MM. Perinatal and hemodynamic evaluation of sildenafil citrate for preeclampsia treatment: a Randomized controlled trial. Obstet Gynecol 2016; 128:253-259.

82. Gillis EE, Mooney JN, Garrett MR, Granger JP, Sasser JM. Sildenafil treatment ameliorates the maternal syndrome of preeclampsia and rescues fetal growth in the dahl salt-sensitive rat. Hypertension 2016; 67:647-653.

83. Stanley JL, Andersson IJ, Poudel R, RuedaClausen CF, Sibley CP, Davidge ST, Baker PN. Sildenafil citrate rescues fetal growth in the catechol-O-methyl transferase knockout mouse model. Hypertension 2012; 59:1021-1028.

84. Abdel Aziz MT, Al-Asmar MF, Mostafa T, Atta H, Rashed L, Sabry D, et al. Assessment of heme oxygenase-1 (HO-1) activity in the cavernous tissues of sildenafil citrate-treated rats. Asian J Androl 2007; 9:377-381.

85. Kweider N, Huppertz B, Kadyrov M, Rath W, Pufe T, Wruck CJ. A possible protective role of Nrf2 in preeclampsia. Ann Anat 2014; 196:268-277.

86. Levytska K, Kingdom J, Baczyk D, Drewlo S. Heme oxygenase-1 in placental development and pathology. Placenta 2013; 34:291-298.

87. Abdel Aziz MT, Mostafa T, Atta H, Rashed L, Marzouk SA, Obaia EM, et al. Oral phosphodiesterase-5 inhibitors: effect of heme oxygenase inhibition on cGMP signalling in rat cavernous tissue. Andrologia 2007; 39:66-70.

88. Abdel Aziz MT, Mostafa T, Atta H, Rashed L, Marzouk SA, Obaia EM, et al. The role of PDE5 inhibitors in heme oxygenase-cGMP relationship in rat cavernous tissues. J Sex Med 2008; 5:1636-1645.

89. Abdel Aziz MT, Mostafa T, Atta H, Wassef MA, Fouad HH, Rashed LA, Sabry D. Putative role of carbon monoxide signaling pathway in penile erectile function. J Sex Med 2009; 6:49-60.

90. Abdel Aziz MT, El Asmer MF, Mostafa T, Atta $\mathrm{H}$, Mahfouz S, Fouad H, et al. Effects of losartan, HO-1 inducers or HO-1 inhibitors on erectile signaling in diabetic rats. J Sex Med 2009; 6:3254-3264.

91. Wareing M, Myers JE, O’Hara M, Baker PN. Sildenafil citrate (Viagra) enhances vasodilatation in fetal growth restriction. J Clin Endocrinol Metab 2005; 90:2550-2555. 
92. von Dadelszen P, Dwinnell S, Magee LA, Carleton $\mathrm{BC}$, Gruslin A, Lee B, et al., Research into Advanced Fetal Diagnosis and Therapy (RAFT) Group. Sildenafil citrate therapy for severe earlyonset intrauterine growth restriction. BJOG 2011; 118:624-628.

93. Dastjerdi MV, Hosseini S, Bayani L. Sildenafil citrate and uteroplacental perfusion in fetal growth restriction. J Res Med Sci 2012; 17:632-636.

94. Dilworth MR, Andersson I, Renshall LJ, Cowley E, Baker P, Greenwood S, et al. Sildenafil citrate increases fetal weight in a mouse model of fetal growth restriction with a normal vascular phenotype. PLoS ONE 2013; 8:e77748.

95. Alatas E, Yagci AB. The effect of sildenafil citrate on uterine and clitoral arterial blood flow in postmenopausal women. Med Gen Med 2004; 6:51.

96. Cavalcanti AL, Bagnoli VR, Fonseca AM, Pastore RA, Cardoso EB, Paixão JS, et al. Effect of sildenafil on clitoral blood flow and sexual response in postmenopausal women with orgasmic dysfunction. Int $\mathbf{J}$ Gynaecol Obstet 2008; 102:115-119.

97. Yang CC, Cao YY, Guan QY, Heiman JR, Kuffel SW, Peterson BT, Maravilla KR. Influence of PDE5 inhibitor on MRI measurement of clitoral volume response in women with FSAD: a feasibility study of a potential technique for evaluating drug response. Int J Impot Res 2008; 20:105-110.

98. Leddy LS, Yang CC, Stuckey BG, Sudworth M, Haughie S, Sultana S, Maravilla KR. Influence of sildenafil on genital engorgement in women with female sexual arousal disorder. J Sex Med 2012; 9:2693-2697.

99. Dmitrovic R, Kunselman AR, Legro RS. Sildenafil citrate in the treatment of pain in primary dysmenorrhea: a randomized controlled trial. Hum Reprod 2013; 28:2958-2965.

100. Hale SA, Jones CW, Osol G, Schonberg A, Badger GJ, Bernstein IM. Sildenafil increases uterine blood flow in nonpregnant nulliparous women. Reprod Sci 2010; 17:358-365.

101.Ramesar SV, Mackraj I, Gathiram P, Moodley J. Sildenafil citrate improves fetal outcomes in pregnant, L-NAME treated, Sprague-Dawley rats. Eur J Obstet Gynecol Reprod Biol 2010; 149:22-26.

102.Maher MA, Sayyed TM, Elkhouly N. Sildenafil citrate therapy for oligohydramnios: a randomized controlled trial. Obstet Gynecol 2017; 129:615620 .

103. Trakakis E, Vaggopoulos V, Sioulas VD,
Panagopoulos P, Grammatikakis I, Ambatzi P, Kassanos D. The contribution of sildenafil (Viagra) to ovarian stimulation with gonadotropins in a woman with poor ovarian response. Gynecol Endocrinol 2014; 30:478-480.

104.Arikan DC, Bakan V, Kurutas EB, Sayar H, Coskun A. Protective effect of tadalafil on ischemia/ reperfusion injury of rat ovary. J Pediatr Surg 2010; 45:2203-2209.

105. Celik M, Aksoy AN, Aksoy H, Aksoy Y, Halici Z. Sildenafil reduces ischemia-reperfusion injury in rat ovary: biochemical and histopathological evaluation. Gynecol Obstet Invest 2014; 78:162-167.

106. Winston AB, Vazhudhi K, Sen S, Thomas E, Benjamin S, Peedicayil J. Inhibition by sildenafil of contractility of isolated non-pregnant human myometrium. J Pharmacol Pharmacother 2015; 6:136-141.

107.Razdorskaia MV, Neĭmark AI, Aliev RT. Modern approaches to the treatment of patients with overactive bladder and urge urinary incontinence. Urologiia 2013; 1:44-46.

108.Chen H, Wang F, Yu Z, Zhang Y, Liu C, Dai S, et al. Efficacy of daily low-dose tadalafil for treating overactive bladder: results of a randomized, double-blind, placebo-controlled trial. Urology 2017; 100:59-64.

109.Chen H, Wang F, Chen W, Ye Xt, Zhou Q, Shao $\mathrm{F}$, et al. Efficacy of daily low-dose sildenafil for treating interstitial cystitis: results of a randomized, double-blind, placebo-controlled trial--treatment of interstitial cystitis/painful bladder syndrome with low-dose sildenafil Urology 2014; 84:51-56.

110.Alekperov RT, Ananyeva LP, Korzeneva EG, Cheremukhina EO. Efficacy and safety of sildenafil in patients with systemic scleroderma. Ter Arkh 2013; 85:60-67.

111.Altabas K, Altabas V, Berković MC, Rotkvić VZ. From cellulite to smooth skin: is Viagra the new dream cream?. Med Hypotheses 2009; 73:118119.

112.Sanchez O, Marié E, Lerolle U, Wermert D, Israël-Biet D, Meyer G. Pulmonary arterial hypertension in women. Rev Mal Respir 2010; 27:e79-e87.

113.Jiménez López-Guarch C, Escribano Subias P, Tello de Meneses R, Delgado Jiménez JF, Sadia Pérez D, Velázquez Martín MT, et al. Efficacy of oral sildenafil as rescue therapy in patients with severe pulmonary arterial hypertension chronically treated with prostacyclin. Long-term results. Rev Esp Cardiol 2004; 57:946-951. 
114.Milman N, Burton CM, Iversen M, Videbaek R, Jensen CV, Carlsen J. Pulmonary hypertension in end-stage pulmonary sarcoidosis: therapeutic effect of sildenafil? J Heart Lung Transplant 2008; 27:329-334.

115.Michelakis E, Tymchak W, Lien D, Webster $\mathrm{L}$, Hashimoto K, Archer S. Oral sildenafil is an effective and specific pulmonary vasodilator in patients with pulmonary arterial hypertension: comparison with inhaled nitric oxide. Circulation 2002; 105:2398-2403.

116.Gomberg-Maitland M, McLaughlin V, Gulati M, Rich S. Efficacy and safety of sildenafil added to treprostinil in pulmonary hypertension. Am J Cardiol 2005; 96:1334-1336.

117. Olfert IM, Loeckinger A, Treml B, Faulhaber M, Flatz M, Burtscher $\mathrm{M}$, et al. Sildenafil and bosentan improve arterial oxygenation during acute hypoxic exercise: a controlled laboratory trial. Wilderness Environ Med 2011; 22:211-221.

118. Watanabe N, Taniguchi H, Kondoh Y, Kimura T, Kataoka K. Clinical efficacy of sildenafil in interstitial pneumonia with pulmonary hypertension. Nihon Kokyuki Gakkai Zasshi 2011; 49:151-155.

119.Lopez-Meseguer M, Berastegui C, Monforte V, Bravo C, Domingo E, Roman A. Inhaled iloprost plus oral sildenafil in patients with severe pulmonary arterial hypertension delays the need for lung transplantation. Transplant Proc 2013; 45:2347-2350.

120.Sun X, Wang K, Wang W, Li B. Clinical study on sildenafil in treatment of pregnant women with pulmonary arterial hypertension. Zhonghua $\mathrm{Fu}$ Chan Ke Za Zhi 2014; 49:414-418.

121.Huang S, DeSantis ER. Treatment of pulmonary arterial hypertension in pregnancy. Am J Health
Syst Pharm 2007; 64:1922-1926.

122. Cartago RS, Alan PA, Benedicto J. Pregnancy outcomes in patients with severe pulmonary hypertension and Eisenmenger syndrome treated with sildenafil monotherapy. Obstet Med 2014; $7: 40-42$.

123. Volkov AV, Nikolaeva EV, Yudkina NN, Kurmukov IA, Nasonov EL. Survival in pulmonary arterial hypertension, associated with connective tissue diseases, treated by sildenafil: results of the prospective study. Ter Arkh 2015; 87:62-67.

124.Rusiecki J, Rao Y, Cleveland J, Rhinehart Z, Champion HC, Mathier MA. Sex and menopause differences in response to tadalafil: 6-minute walk distance and time to clinical worsening. Pulm Circ 2015; 5:701-706.

125.Denardo SJ, Wen X, Handberg EM, Bairey Merz CN, Sopko GS, Cooper-Dehoff RM, Pepine CJ. Effect of phosphodiesterase type 5 inhibition on microvascular coronary dysfunction in women: a Women's Ischemia Syndrome Evaluation (WISE) ancillary study. Clin Cardiol 2011; 34:483-487.

126. Bortolotti M, Mari C, Giovannini M, Pinna S, Miglioli M, Pandolfo N. Effects of sildenafil on esophageal motility of normal subjects. Dig Dis Sci 2001; 46:2301-2306.

127.Jansson PA, Murdolo G, Sjögren L, Nyström B, Sjöstrand M, Strindberg L, Lönnroth P. Tadalafil increases muscle capillary recruitment and forearm glucose uptake in women with type 2 diabetes. Diabetologia 2010; 53:2205-2208.

128.Murdolo G, Sjöstrand M, Strindberg L, Lönnroth P, Jansson PA. The selective phosphodiesterase-5 inhibitor tadalafil induces microvascular and metabolic effects in type 2 diabetic postmenopausal females. J Clin Endocrinol Metab 2013; 98:245254. 